\title{
Surprise greetings to Professor Fritz Scholz
}

\author{
György Inzelt ${ }^{1}$
}

Published online: 4 July 2015

(C) Springer-Verlag Berlin Heidelberg 2015

I am writing this Editorial for the Journal of Solid State Electrochemistry which has existed for 19 years. Its birth and continuous existence are due to one person, the Spiritus Rector of the journal, who is called simply Editor-in-Chief nowadays. May I remind you, dear readers, that the expression, spiritus rector was used by alchemists for a substance or distilled product which was believed to be capable of transmuting metals into gold. Our forefathers' dream has not become true but Professor Fritz Scholz has been successful. This, alone, would be enough to justify celebrating his 60th birthday on the pages of this Journal. However, there are many other reasons that I write this Editorial. I am grateful to Dr Steffen Pauly, the Editorial Director of Chemistry at Springer, for the idea that in this case we do not use our favourite Editorial Manager, and in this way it will be a real surprise for Fritz. Knowing his modest personality I am not sure he wants it, but I hope he will not be angry as a result of this celebration.

It is truly a privilege to work with Fritz. I have always admired his continually new and newer ideas, and the way he works hard to realize a project, without despair. At least he seldom shares his despair; he is always full of enthusiasm for the cause. In this way, he can persuade colleagues to join a project, and he very politely pushes them to write their book chapter, entry, or papers before the deadline. All of us know that this is an extremely hard task.

Fritz has made me, also, work hard during the last 20 years. Our common enterprises have been the books "Electroanalytical

György Inzelt

inzeltgy@chem.elte.hu

1 Department of Physical Chemistry, Institute of Chemistry, Eötvös Loránd University, Pázmány Péter sétány 1/A, 1117 Budapest, Hungary
Methods" (2002, 2nd edn 2010, Springer), "Electrochemical Dictionary" (2008; 2nd edn. 2012, Springer), volume 7 of the "Encyclopedia of Electrochemistry" (2006, Wiley-VCH), "Handbook of Reference Electrodes" (2013, Springer), "Electrochemistry in a divided world" (2015, Springer), and a book on "Conducting Polymers" (2008, 2nd edn 2012, Springer) which appeared in the series "Monographs in Electrochemistry", Springer. This series, because of the outstanding editorship of Professor Scholz has become an authoritative source in electrochemistry during the years in which modern topics of electrochemistry have been presented. The special issue of J. Solid State Electrochemistry in 2011 "Electrochemistry—past, present and future" was a success. All of these publications were initiated by Fritz.

Last but not least, in 2014 he founded the journal "ChemTexts-The Textbook Journal" (Springer) which introduces a completely new concept in scientific publishing: the provision of texts for educational purposes that present the current state of knowledge.

It is always a pleasure working with Fritz as co-editor or coauthor but the lions' share in all these works always belongs to Fritz. Any joint work with Fritz is rather demanding, because he is a very fastidious person, and expects the same standard of quality and professionalism from his partners. He is fastidious not only concerning scientific matters but also corrects all formal issues, for example the correct notation of physical quantities or romanization of Cyrillic letters. It is, however, fun to work with Fritz because of high-level discussion with him.

Besides his editorships Professor Scholz is a prominent scientist with numerous contributions to different fields of contemporary electrochemistry. Probably the most important area in which he has made both fundamental and practical contributions is the field of solid-state electrochemistry of microparticles attached to a metal or paraffin-impregnated 
graphite surface. This has led to new advances in the electroanalysis of solid samples, and made it possible to investigate the phase transitions of solid materials, which has certainly increased the scope of electrochemistry. He introduced threephase electrodes to determine the Gibbs energies of ion transfer between immiscible liquids. In recent years he has been studying the interaction of free oxygen radicals with metal surfaces, and the interaction of liposomes with the surface of mercury electrodes to assess membrane properties. He has published more than 300 scientific papers and received more than 5500 citations. It was, indeed, highly appropriate that the community of electrochemists expressed its esteem and respect by awarding him the ISE Fellowship in 2015.

Another interest we have in common is the history of electrochemistry, laying the stress not only on the development of science but also, with emphasis, on the human side. Fritz is not only an eminent electrochemist but also a bright intellectual with a wide knowledge in many branches of human culture. Indeed, Fritz personifies a natural philosopher in its classical meaning.
When, on special occasions, we discuss scientists on the pages of a scientific journal we usually praise their scientific achievements. However, the picture would not be complete mentioning Fritz's exceptional kindness, helpfulness, and hospitality which have been experienced by many of us.

When I think of Fritz, a verse of a great Hungarian poet comes to my mind

Now take your place and tell your tale. Begin.

We listen. There are some who happily

Turn their faces. On you their gaze alights,

A European true among the whites.

(Attila József: “Thomas Mann's welcome”, 1937, translation M. Slipp)

According to alchemists, the spiritus rector was also an elixir which was supposed to prolong life indefinitely. I believe, on the occasion of Fritz's 60th birthday, it is sufficient to wish for "Bis hundert und zwanzig".

\section{Dear Fritz!}

On behalf of all your friends and colleagues I wish you Many happy returns of the day! 